\title{
SIMULATION-BASED OPTIMIZATION USING SIMULATED ANNEALING FOR OPTIMAL EQUIPMENT SELECTION WITHIN PRINT PRODUCTION ENVIRONMENTS
}

\author{
Sudhendu Rai \\ Ranjit Kumar Ettam \\ Xerox Corporation \\ 800 Phillips Road \\ Webster, NY 14450 USA
}

\begin{abstract}
Xerox has invented, tested, and implemented a novel class of operations-research-based productivity improvement offerings that has been described in Rai et al. (2009) and was a finalist in the 2008 Franz Edelman competition. The software toolkit that enables the optimization of print shops is data-driven and simulation based. It enables quick modeling of complex print production environments under the cellular production framework. The software toolkit automates several steps of the modeling process by taking declarative inputs from the end-user and then automatically generating complex simulation models that are used to determine improved design and operating points. This paper describes the addition of another layer of automation consisting of simulation-based optimization using simulated-annealing that enables automated search of a large number of design alternatives in the presence of operational constraints to determine a cost-optimal solution. The results of the application of this approach to a real-world problem are also described.
\end{abstract}

\section{INTRODUCTION}

Xerox has invented, tested, and implemented a novel class of operations-research-based productivity improvement offerings, marketed as Lean Document Production (LDP), for the $\$ 100$ billion printing industry in the United States. The LDP software toolkit automates several steps of the modeling process by taking declarative inputs from the end-user and then automatically generating complex simulation models that are used to determine improved design and operating points for the print shops. In this paper, we describe the addition of another layer of automation to the LDP toolkit consisting of a simulated annealing based simulation optimization that enables automated search of a large number of design alternatives in the presence of operational constraints to determine a cost-optimal solution for the print production environment.

The printing industry is highly fragmented with thousands of print shops that are geographically distributed. This approach lends itself to being utilized for optimizing print shops across multiple geographies by users less skilled in the art of simulation modeling and optimization thereby allowing unprecedented scalability of a simulation-based optimization toolkit to a wide user-base. Users are able to utilize the simulation-based optimization toolkit to make complex design and operational decisions and develop optimized designs without having to actually go through the arduous task of building the simulation models and the associated optimization framework around it.

This paper is organized as follows. In Section 2, a review of prior art is provided. Section 3 provides a characterization of the print-production environment. Section 4 describes the problem being addressed in 


\section{Rai and Ettam}

this paper. Section 5 provides an overview of the Lean Document Production solution and the LDP toolkit. Section 6 describes the existing procedure of selecting the optimal printing equipment. Section 7 describes the simulation-based optimization using the LDP toolkit. Section 8 describes some applications and case studies using a real-world example. Section 9 describes future work planned in this area.

\section{PRIOR ART}

The problem of constrained simulation optimization over a finite discrete set of decision variables has recently started receiving some attention. Andradóttir, Goldsman, and Kim (2005) presented a two phase statistically valid procedure that detects feasibility of systems in the presence of one constraint with a prespecified probability of correctness. Batur and Kim (2005) extended Andradóttir, Goldsman, and Kim (2005) procedure to the case of multiple constraints. Szechtman and Yücesan (2008) considered the problem of feasibility determination in stochastic settings. They provided an algorithm for optimal sampling allocations using large deviation theory. Pujowidianto et al. (2009) proposed an optimal computing budget allocation framework for selecting the best design from a discrete number of alternatives in the presence of a stochastic constraint via simulation experiments. Kabirian and Olafsson (2009) proposed iterative heuristic algorithm with a limitation on simulation budget or probability of correctness for selecting the best solution in the presence of stochastic constraints. Luo and Lim (2011) propose a new method that converts constrained optimization into the unconstrained optimization by using the Lagrangian function.

The approaches discussed above either visit all the designs or convert the problem in to a single objective function to find the best system. Suppose we conduct $\mathrm{n}$ simulation replications for each of $\theta$ designs, we need $\mathrm{n} \theta$ total simulation replications. If the precision requirement is high, and if the total number of designs in a problem is large, then $\mathrm{n} \theta$ can be very large, making the system evaluation computationally intensive using the existing methods. In such cases, random search algorithms such as simulated annealing, tabu search and genetic algorithms proves to be the best choice. Simulated annealing which was proposed by Kirkpatrick, Gelatt, and Vecchi (1983) has shown successful applications in a wide range of combinatorial optimization problems, and this fact have motivated researchers to use simulated annealing in many simulation optimization problems. But these search techniques need to be adapted for the stochastic environment associated with discrete-event simulation optimization.

Haddock and Mittenthal (1992) have investigated the feasibility of using a simulated annealing algorithm in conjunction with a simulation model. Alkhamis and Ahmed (2004) have developed a variant of simulated annealing algorithm for solving discrete unconstrained stochastic optimization problems by using a constant temperature and convergence criteria as the number of visits made by the different states in the first m-iterations to estimate the optimal solution. Prudius and Andradóttir (2005) have presented two variants of the simulated annealing algorithm with a decreasing cooling schedule that are designed for solving unconstrained discrete simulation optimization problems. Ahmed, Alkhamis, and Hasan (1997) presented the simulated annealing algorithm for solving stochastically constrained simulation optimization systems. They perform student $t$ test to check the feasibility of current solution and restricted the transition moves to only feasible configurations.

Unlike ranking and selection procedures, the application of meta-heuristics techniques to simulation optimization problems in stochastic settings may not guarantee the probability of correct selection of a solution. But in most of the cases we observe that they converge to optimal or near optimal solutions in reasonable amount of time which is most desirable in many real world applications. In this paper we have presented the modified simulated annealing which can handle uncertainty in simulation output and stochastic constraint(s). The algorithm starts with an initial feasible solution and utilizes a decreasing cooling schedule for identifying the optimal solution. To estimate the objective functions we make use of all the observations obtained so far at that solution. We perform student's t hypothesis test similar to Ahmed, Alkhamis, and Hasan (1997) procedure to determine the feasibility of a solution at current iteration. Unlike in Ahmed, Alkhamis, and Hasan (1997) procedure, our algorithm does not restrict the neighborhood search to feasible moves only. 


\section{Rai and Ettam}

\section{CHARACTERIZATION OF WORKFLOW IN PRINT SERVICE CENTER ENVIRONMENTS}

Print service center can be classified into three categories based on the activity that they performtransaction printing, on-demand publishing, or a combination of both. A transaction-printing environment produces documents such as checks, invoices, etc. Each document set is different. Mail metering and delivery are part of the workflow. On-demand publishing environments focus on producing several copies of identical documents with more finishing options such as cutting, punching and binding. Examples of such products include books, sales brochures and manuals. Other environments perform both types of document production simultaneously with varying emphasis on each one.

The document production steps associated with print jobs are indicated in Figure 1. Typically print service centers have departments that support individual steps of this workflow. Each department supports many different types of internal workflows resulting from the use of different types of software tools, printing machines types (e.g., offset, digital) and a variety of finishing equipment (such as cutting, binding, laminating, shrink-wrapping). For further description of each of the steps, we refer the reader to Rai et al. (2009).

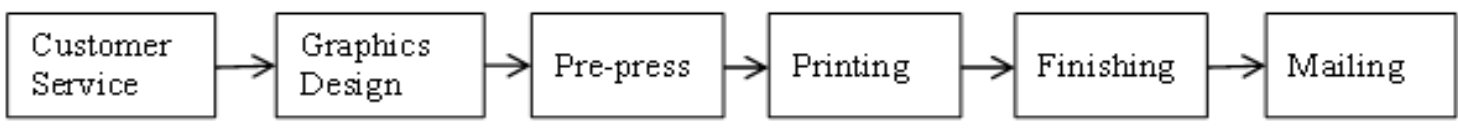

Figure1: A print production workflow showing the various production operations.

\section{PROBLEM DESCRIPTION}

Print service centers experience many sources of variability. They exhibit high levels of task size variations, routing complexity and demand fluctuations as shown in Figure 2 that makes them hard to optimize. These service centers are primarily make-to-order service systems that cater to specific requests of each incoming customer. The incoming service requests have random arrival and due-date requirements that vary from job to job and often exhibits variability within the same job-type. The size of the jobs is often characterized by highly non-normal distributions and sometimes fat-tail distributions (Rai 2008).
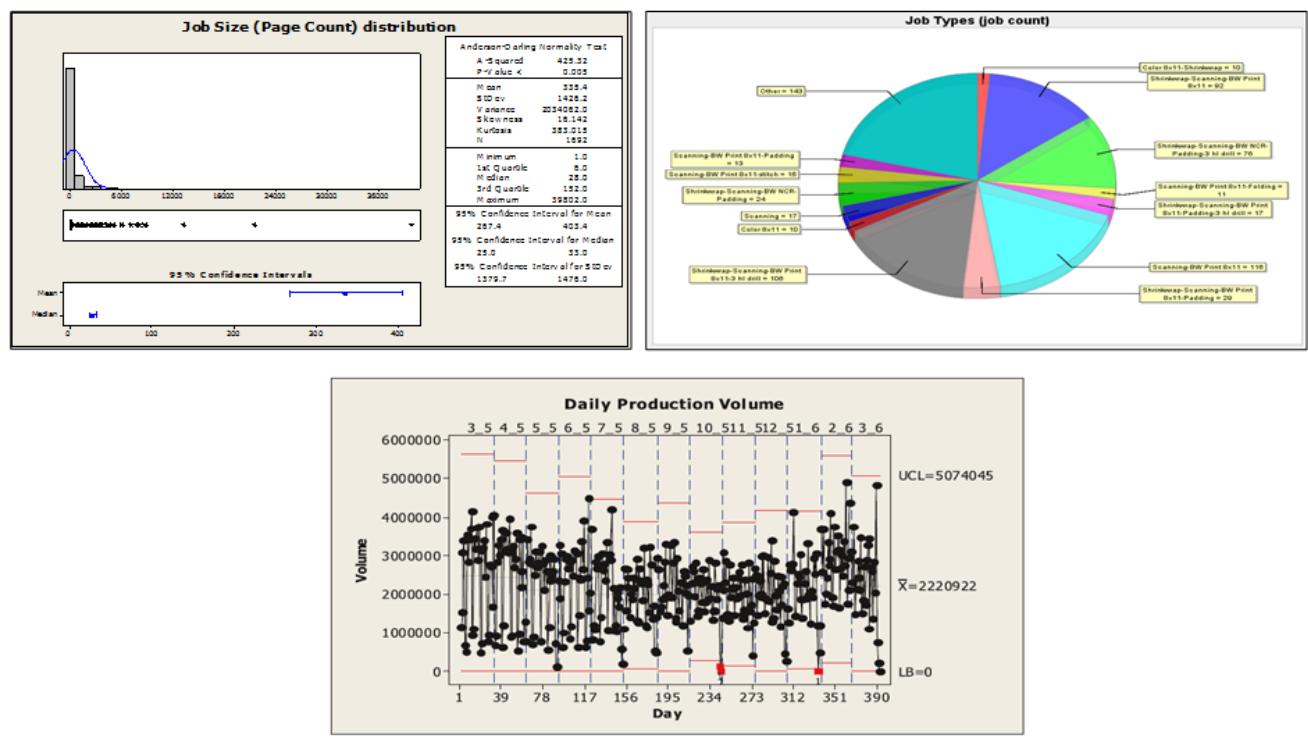

Figure 2: Multiple sources of variability in a print production environment such as power law job-size distributions, multiple co-existent job types and high demand fluctuation. 


\section{Rai and Ettam}

In addition to the above challenges, print shops also experience long bid times, variability in labor and equipment characteristics etc. The LDP tool kit automates the workflow modeling and analysis of print service center. In order to optimize the cost and performance of print service center, the user manually evaluates a limited number of designs and selects the best design among them. While this process allows users to evaluate multiple configuration scenarios manually, it also can tend to be labor-intensive and time consuming and could lead to sub-optimal solutions. In this paper we have described an automated method for selecting the least cost optimal solution for print service center out of a large number of solutions by integrating the optimization algorithm with the LDP solution.

\section{THE LDP SOLUTION FOR PRINT SERVICE CENTER ENVIRONMENT}

To address the complexity of operations associated with the print production processes, the service center resources are organized in autonomous cells (Rai et al. 2009). As a result, the most common jobs can be finished autonomously inside (at least) one of these cells. Figure 3 shows how traditional print service centers are organized based on a departmental structure operated by specialized workers and compares it to the redesigned operational framework based on autonomous cells where diverse pieces of equipment are collocated and operated by cross-trained workers.
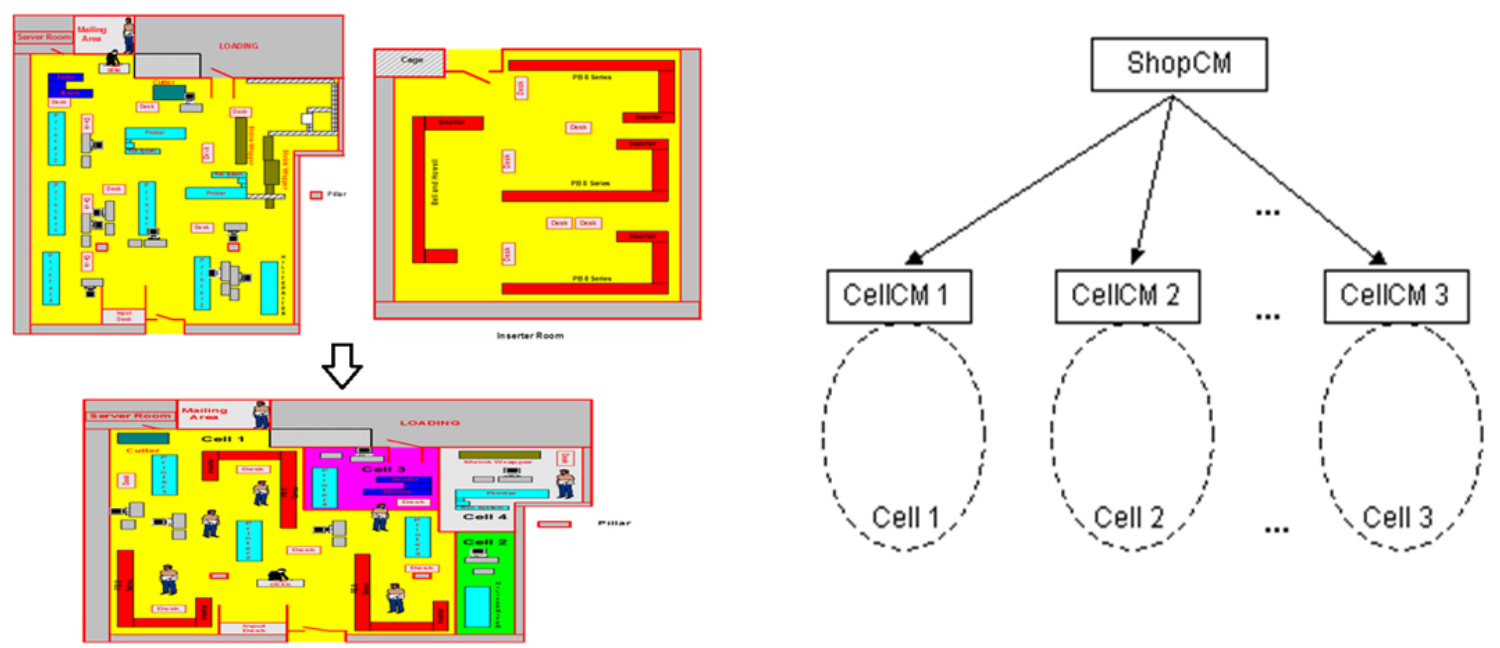

Figure 3: Figure showing how a departmental configuration of a print service center is transformed into a cellular structure utilizing autonomous cells and the corresponding two-level architecture for the Lean Document Production Controller .

To orchestrate the flow and control of jobs through the parallel hierarchical cell structure, the Lean Document Production Controller (LDPC) uses a 2-level architecture (Figure 3) for production management. The LDPC has:

- A service center controller module (Service centerCM) - high-level controller, in charge of global service center management.

- Several cell controller modules (CellCMs) - low-level controllers, in charge of local management inside cells. 


\section{Rai and Ettam}

\subsection{Simulation}

Simulation is performed to assess the results of improvements resulting from changes in workflow grouping, operator cross-training, grouping diverse equipment into autonomous cells and scheduling policies. Building discrete-event simulation models is often a time-intensive effort especially when various scenarios have to be investigated to determine improved solutions. To facilitate the model building process, the LDP tool semi-automatically builds the simulation models from a declarative user-interface (see Figure 4). This allows for fast and efficient evaluation of a large number of what-if scenarios and greatly aids in determining an improved solution out of a large search space.

The user specifies the equipment characteristics, elements of the cell, scheduling policies, number of operators and their skill level, and workflow/job characteristics as inputs to the simulation model using the LDP user-interface(see Figure 4). Before the shop is simulated, the user schedules the jobs automatically using the two level scheduling architecture described above. Next the tool simulates the print service center and results the performance metrics such as average turnaround time, number of late jobs, operator and equipment utilization etc., as shown in Figure 4.

\section{LDP Input}

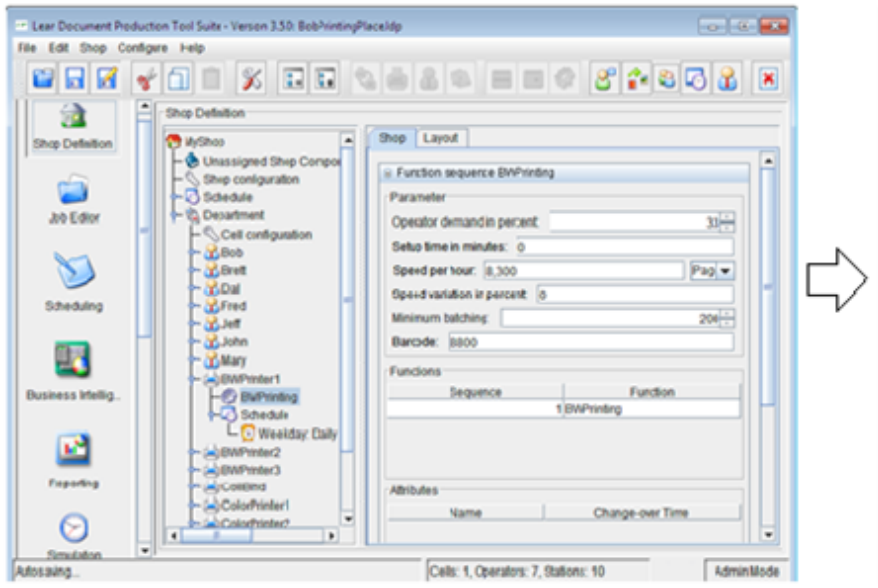

\section{LDP Output}

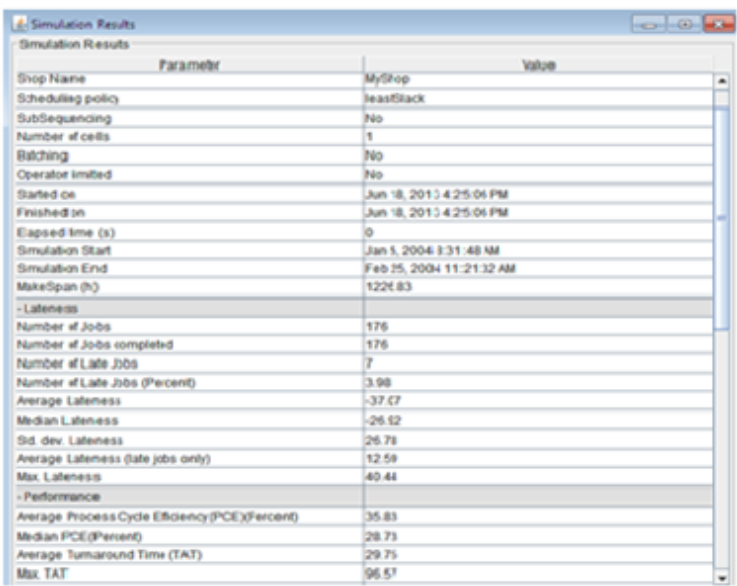

Figure 4: Illustrates the user interface for defining the printing equipment, operators and shop policies, and simulation results for a sample print service center.

\section{EXISTING PROCEDURE FOR SELECTING OPTIMAL EQUIPMENT DESIGN IN PRINT SERVICE CENTER}

The selection of optimal printing equipment in the print service center is currently carried out manually and exhaustively. The user first defines the necessary equipment type, cost and other characteristics (speed, setup time, failure and repair rates etc.,) in each cell, The job workflow characteristics and other shop operating policies (job sequencing policy, batching and work in progress etc.,) are collected from the shop and loaded in to the LDP tool. An equipment design is defined as a combination of different number of equipment types in each cell. The user has to create different equipment designs that he is interested on by varying the number of equipment's of each type in each of the cell. Each of these equipment design is simulated $\mathrm{N}$ number of times in order to account for the simulation randomness. Then, the mean performance measure of interest and total cost of the equipment is computed. Finally the user selects the equipment design that has the least cost and meets the desired print service center performance goal as specified by the user. This process of evaluating multiple design configuration is labor-intensive, time 


\section{Rai and Ettam}

consuming and can lead to sub-optimal solutions. Figure 5 illustrates the detailed process flow diagram of existing procedure.

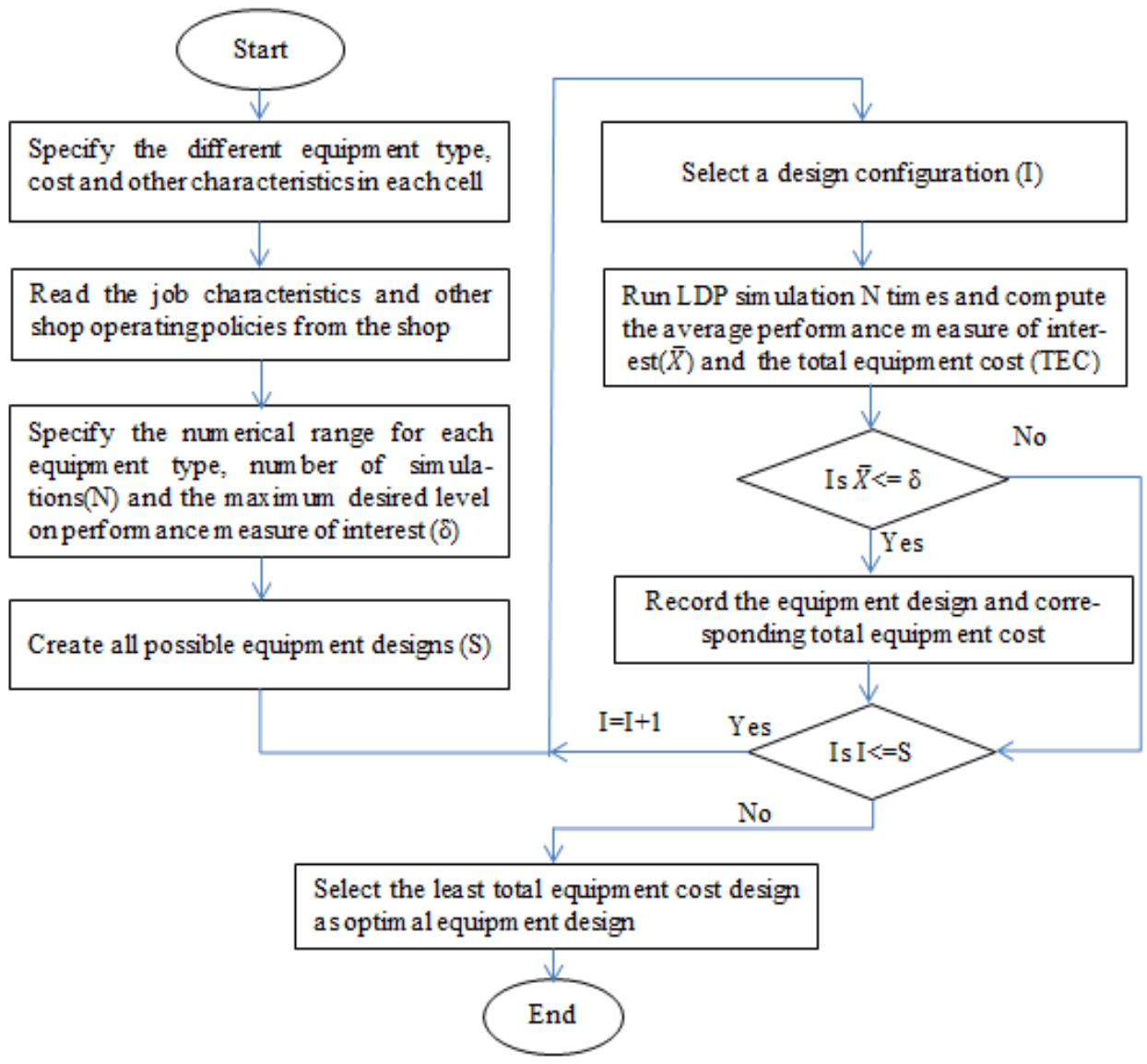

Figure 5: Illustrates the existing procedure for selecting optimal equipment configuration using LDP tool in print service center.

\section{SIMULATION BASED OPTIMIZATION USING THE LDP TOOLKIT}

The main idea in this study is to integrate the optimization routine and simulation module within the LDP toolkit that embodies many elements of shop specification and modeling automation. This enables the automatic search of optimal solution for the print production service center. For more detailed discussion, applications and benefits of integrating optimization with simulation can be found in Fu et al. (2000), Harkan and Hariga (2007), Zeng and Yang (2009), and Sandeman et al. (2010).

\subsection{Problem Formulation}

The problem of selecting the cost-optimal solution for the print production environment in the presence of stochastic operational constraints over a large number of design alternatives can be mathematically formulated as below.

Objective:

$\min _{\mathrm{X}_{\mathrm{k}} \in \mathrm{S}} f_{0}\left(X_{k}\right)$

Subject to:

$\mathrm{f}_{1}\left(X_{k}\right) \leq \delta$;

$\mathrm{lb}_{\mathrm{ij}} \leq \mathrm{x}_{\mathrm{ij}} \leq \mathrm{ub} \mathrm{b}_{\mathrm{ij}}, \mathrm{i}=1 . \mathrm{n}_{\mathrm{j}}, \mathrm{j}=1 . . \mathrm{m}$;

$\mathrm{X}_{\mathrm{k}}=\left[\mathrm{x}_{\mathrm{ij}}\right]$; 


\section{Rai and Ettam}

where $\mathrm{S}$, the search space, is a large, finite, and discrete set of equipment design configurations; $\mathrm{X}_{\mathrm{k}}$ is the $\mathrm{k}^{\text {th }}$ equipment design configuration, which is the vector combination in the number of each type of equipment in each cell; $\mathrm{k}$ is the index of equipment design configuration; $\mathrm{x}_{\mathrm{ij}}$ is the number of $\mathrm{i}^{\text {th }}$ type of equipment in $\mathrm{j}^{\text {th }}$ cell; $\mathrm{n}_{\mathrm{j}}$ is the number of unique equipment types in cell $\mathrm{j}$; $\mathrm{m}$ represents the total number of cells in the print service center; $\mathrm{lb}_{\mathrm{ij}}$ and $\mathrm{ub}_{\mathrm{ij}}$ are the lower and upper bounds on the number of $\mathrm{i}^{\text {th }}$ type of equipment in $\mathrm{j}^{\text {th }}$ cell; $\mathrm{f}_{0}\left(\mathrm{X}_{\mathrm{k}}\right)$ is the total equipment cost defined as $C_{i j} \times x_{i j}$, where $\mathrm{C}_{\mathrm{ij}}$ is the cost of $i^{\text {th }}$ equipment in $j^{\text {th }}$ cell; $f_{1}\left(X_{k}\right)$ is the print service center performance measure such as average turnaround time/ number of late jobs/ maximum average turnaround time, which cannot be evaluated exactly, but needs to be estimated via LDP simulation. Let $A_{k l}$ be the print service center performance observation observed from simulation replication 1 of system $\mathrm{k}$, then $f_{1}\left(X_{k}\right)=E\left[A_{k l}\right]$; and $\delta$ is the maximum desirable level on print service center performance measure.

\subsection{Modified Simulated Annealing Algorithm}

Here, we present the modified simulated annealing algorithm used for solving the problem (1). This algorithm starts with an initial feasible solution and utilizes a decreasing cooling schedule for identifying the optimal solution. The general purpose simulated annealing doesn't handle stochastic constraints when it moves from one solution to another. A solution is feasible if it meets the print service center performance goal as specified by the user. To test the feasibility of a solution, we do the following procedure proposed by Ahmed, Alkhamis, and Hasan (1997):

Let us consider, an arbitrary stochastic constraint $g(\theta) \leq \delta$, where $g(\theta)$ is the stochastic simulation output for design $\theta$ and $\delta$ being the maximum desirable level. Letting $g_{i}(\theta)$ denote the $i^{\text {th }}$ simulation replication and running simulation $\mathrm{n}$ times, the estimate for $\mathrm{g}(\theta)$ could be determined over $\mathrm{n}$ replications as $\hat{g}(\theta)=\sum_{i=1}^{n} g_{i}(\theta) / n$ and the variance of $\hat{g}(\theta)$ is given by $\widehat{\sigma}_{\hat{g}(\theta)}=\sum_{i=1}^{n}\left(g_{i}(\theta)-\hat{g}(\theta)\right)^{2} / n-1$. Then the

feasibility conditions are as follows. $\mathrm{H} 0: \hat{\mathrm{g}}(\theta)<=\delta, \mathrm{H} 1: \hat{\mathrm{g}}(\theta)>\delta$.

We accept H0, if $\omega=\widehat{\mathrm{g}}(\theta)+\mathrm{t}_{\mathrm{n}-1,1-\alpha} \times \widehat{\sigma}_{\hat{\mathrm{g}}(\theta)} / \sqrt{\mathrm{n}} \leq \delta$, where $\mathrm{n}-1$ is the degrees of freedom, 1- $\alpha$ is

the upper critical point for the $t$ distribution and $\widehat{\sigma}_{\hat{g}(\theta)}$ denotes the standard deviation of $\hat{g}(\theta)$.

Unlike in Ahmed, Alkhamis, and Hasan (1997) procedure, our algorithm does not restrict the neighborhood search to feasible moves only. In their method the temperature length (M) parameter is not incremented until a neighboring feasible solution is found, resulting in unknown/more number evaluations. When the probability of finding a feasible neighborhood solution is very low, this may result in indefinite looping. In the modified simulated annealing algorithm, the temperature length (L) parameter is incremented irrespective of the feasibility of the neighborhood solution, providing more control on the total number of evaluations by the algorithm. Let $T_{0}$ be the initial temperature, $T_{f}$ be the final ture $\left(T_{0} / T_{\text {depth }}\right)$ and $\mathrm{r}$ the temperature decay rate. This results in the following series of annealing temper-

atures:

$$
\begin{gathered}
T_{0}, T_{0} \times r, T_{0} \times r^{2}, T_{0} \times r^{3} \ldots \ldots+T_{0} \times r^{n}, \\
T_{f}=\frac{T_{0}}{T_{\text {depth }}}=T_{0} \times r^{n}, \\
n=\frac{\log ^{1} / T_{\text {depth }}}{r} .
\end{gathered}
$$

If the number of times to search a neighborhood solution at a given temperature is $\mathrm{L}$, then the number of evaluations is $n \times L$. To estimate the performance measure the algorithm makes use of all the historical observations obtained at that solution. Next, we define the following: 
Definition 1 The search space $S$ is a set of equipment design configurations whose cardinality is $\prod_{j=1}^{m} \prod_{i=1}^{n_{j}}\left(u b_{i j}-l b_{i j}+1\right)$

Definition 2 For each $X_{k} \in S$, there exists a subset $N(\theta)$ of $S-\left\{X_{k}\right\}$ which is called the set of neighbors of $X_{k}$, such that each point in $N(\theta)$ can be reached from $X_{k}$ in a single transition.

Parameters: Number of times to run the simulations at design $\left(\mathrm{X}_{\mathrm{k}}\right): \mathrm{n}$

Temperature depth: $\mathrm{T}_{\text {depth }}$

Temperature decay rate: $r$

Maximum desirable level of secondary performance measure: $\delta$

No of times to search a neighborhood solution at a given temperature: $\mathrm{L}$

Significance value for t-test: $\alpha$

Step 1. Set: feasibility $=$ false

Step 2. Begin Loop: While Until feasibility=false

Step 3. Obtain Initial Design Configuration: $X_{i} \in S$

Step 4. Generate observations $\left\{\mathrm{f}_{0}\left(\mathrm{X}_{\mathrm{i}}\right)\right\}_{\mathrm{j}=1}^{\mathrm{n}},\left\{\mathrm{f}_{1}\left(\mathrm{X}_{\mathrm{i}}\right)\right\}_{\mathrm{j}=1}^{\mathrm{n}}$

Step 5. Evaluate $: \hat{\mathrm{f}}_{0}\left(\mathrm{X}_{\mathrm{i}}\right), \widehat{\mathrm{f}}_{1}\left(\mathrm{X}_{\mathrm{i}}\right), \hat{\sigma}_{\hat{\mathrm{f}}_{0}\left(\mathrm{X}_{\mathrm{i}}\right)}, \hat{\sigma}_{\hat{\mathrm{f}}_{1}\left(\mathrm{X}_{\mathrm{i}}\right)}$ and $\mathrm{t}_{\mathrm{n}-1,1-\alpha}$

Step 6. IF $\omega \leq \delta$ Then feasibility $=$ true

Step 7. End Loop

Step 8. Set: value $=\hat{\mathrm{f}}_{0}\left(\mathrm{X}_{\mathrm{i}}\right), \mathrm{T}_{\text {initial }}=$ value $/ 2, \mathrm{~T}_{\text {final }}=\mathrm{T}_{\text {initial }} / \mathrm{T}_{\text {depth }}$

Step 9. Begin Loop: While Until $\mathrm{T} \geq \mathrm{T}_{\text {final }}$

Step 10. Set : value old $=$ value

Step 11. Begin Loop : do $\mathrm{j}=1 \ldots . . \mathrm{L}$

Step 12. Set: feasibility=false

Step 13. Get Neighborhood Design $X_{j} \in N\left(X_{i}\right)$, where $N(\theta)$ is the set of neighborhood of $\theta, \theta \in S$

Step 14. Generate observations $\left\{\mathrm{f}_{0}\left(\mathrm{X}_{\mathrm{j}}\right)\right\}_{\mathrm{j}=1}^{\mathrm{n}},\left\{\mathrm{f}_{1}\left(\mathrm{X}_{\mathrm{j}}\right)\right\}_{\mathrm{j}=1}^{\mathrm{n}}$

Step 15. Evaluate : $\hat{\mathrm{f}}_{0}\left(\mathrm{X}_{\mathrm{j}}\right), \widehat{\mathrm{f}}_{1}\left(\mathrm{X}_{\mathrm{j}}\right), \hat{\sigma}_{\hat{\mathrm{f}}_{0}\left(\mathrm{X}_{\mathrm{j}}\right)}, \hat{\sigma}_{\hat{f}_{1}\left(X_{j}\right)}$ and $t_{n-1,1-\alpha}$

Step 16. IF $\omega \leq \delta$ Then feasibility=true

Step 17. IF feasibility=true Then

Step 18. value $_{\text {new }}=\hat{\mathrm{f}}_{0}\left(\mathrm{X}_{\mathrm{j}}\right)$

Step 19. Evaluate: $d$ elta $=$ value $_{\text {new }}$-value and generate $\mathrm{U}_{\mathrm{k}} \sim \mathrm{U}[0,1]$

Step 20. IF delta $<0$ OR $e^{- \text {delta } /} \mathrm{T} \geq \mathrm{U}_{\mathrm{k}}$ then value $=$ value $_{\text {new }}$ and $\mathrm{X}_{\mathrm{i}}=\mathrm{X}_{\mathrm{j}}$

Step 21. End IF

Step 22. End IF

Step 23. End IF

Step 24. Next j

Step 25. End Loop

Step 26. $T=r \times T$

Step 27. End Loop

Step 28. Return Optimum Design Configuration: $X_{i}^{*}=X_{i}$

Step 29. Return Optimum Value: $\hat{\mathrm{f}}_{0}\left(\mathrm{X}_{\mathrm{i}}^{*}\right)$

Step 30. End 


\section{Rai and Ettam}

\section{APPLICATION AND CASE STUDY}

This section illustrates the selection of optimal printing equipment configuration in a transaction print shop which has two cells and six stations using existing and simulation based optimization approach with two different test cases. Table 1 shows the printing equipment in each cell and their fixed cost. In both the test cases, the total equipment cost is deterministic and defined as $C_{i j} \times x_{i j}$ where, $\mathrm{C}_{\mathrm{ij}}$ is the fixed cost of $\mathrm{i}^{\text {th }}$ station in $\mathrm{j}^{\text {th }}$ cell and $\mathrm{x}_{\mathrm{ij}}$ is the number of $\mathrm{i}^{\text {th }}$ type of equipment in $\mathrm{j}^{\text {th }}$ cell. The print service center performance measure $\left(f_{1}\left(X_{k}\right)\right)$ is problem specific and can only be estimated by running simulations.

Table 1: The printing equipment in each cell and their fixed cost.

\begin{tabular}{|l|l|l|}
\hline Cell & Station & Fixed Cost \\
\hline Cell One & Printer A & 2448874 \\
\hline Cell One & Inserter A & 423366 \\
\hline Cell One & Inserter B & 1443304 \\
\hline Cell One & Printer B & 2448874 \\
\hline Cell Two & Printer C & 3000000 \\
\hline Cell Two & Inserter B & 1443304 \\
\hline
\end{tabular}

Job data for a period of 10 days is collected from the print shop with 2692 jobs in the period. The number of equipment of each function/station type in a cell is varied between 1-3 and the total number of possible equipment configuration is 729 . Table 2 illustrates a sample of all the possible equipment configurations.

Table 2: A sample of equipment configuration.

\begin{tabular}{|l|ll|ll|ll|l|l|l|}
\hline Design & $\begin{array}{l}\text { Number of } \\
\text { No }\end{array}$ & $\begin{array}{l}\text { Printer A } \\
\text { stations in } \\
\text { Cell One }\end{array}$ & $\begin{array}{l}\text { Inserter A } \\
\text { stations in } \\
\text { Cell One }\end{array}$ & $\begin{array}{l}\text { Inserter } \\
\text { stations } \\
\text { Cell One }\end{array}$ & $\begin{array}{l}\text { B } \\
\text { in }\end{array}$ & $\begin{array}{l}\text { Printer B sta- } \\
\text { tions in Cell } \\
\text { One }\end{array}$ & $\begin{array}{l}\text { Pumber of } \\
\text { Printer C } \\
\text { stations in } \\
\text { Cell Two }\end{array}$ & $\begin{array}{l}\text { Number of } \\
\text { Inserter B } \\
\text { stations in } \\
\text { Cell Two }\end{array}$ \\
\hline 1 & 1 & 1 & 1 & 1 & 1 & 1 \\
\hline 2 & 1 & 1 & 1 & 1 & 1 & 2 \\
\hline. &. &. &. &. &. &. &. \\
\hline. &. &. &. & - &. &. \\
\hline 728 & 3 & 3 & 3 & 3 & 3 & 2 \\
\hline 729 & 3 & 3 & 3 & 3 & 3 & 3 \\
\hline
\end{tabular}

\subsection{Test Case 1}

In this problem, we have considered the print service center performance measure $\left(f_{1}\left(X_{k}\right)\right)$ as average turnaround time less than or equal to 5 hours. The average turnaround time is defined as the arithmetic average of turnaround times (difference between the completion time and arrival time of job) of all the jobs. Table 3 illustrates the optimal and/or near optimal equipment configuration using existing approach with $\mathrm{N}$ equal to 30 ( $\mathrm{N}$ is the number of simulations replications for each design configuration) and simulation optimization approach with the parameters $n=5, \mathrm{~L}=5, T_{\text {depth }}=100, \mathrm{r}=0.9$ and $\alpha=0.01$ for three different simulated annealing runs. 


\section{Rai and Ettam}

Table 3: Test case 1 results summary.

\begin{tabular}{|c|c|c|c|c|c|}
\hline & \multicolumn{2}{|c|}{$\begin{array}{l}\text { Exhaustive Search } \\
\text { (Existing Approach) }\end{array}$} & \multicolumn{3}{|c|}{ Simulation Optimization Approach } \\
\hline & $1^{\text {st }}$ best & $2^{\text {nd }}$ best & Run 1 & Run 2 & Run 3 \\
\hline No of Printer A stations in Cell One & 1 & 1 & 1 & 1 & 1 \\
\hline No of Inserter A stations in Cell One & 1 & 2 & 1 & 1 & 2 \\
\hline No of Inserter B stations in Cell One & 3 & 3 & 3 & 3 & 3 \\
\hline No of Printer B stations in Cell One & 1 & 1 & 1 & 1 & 1 \\
\hline No of Printer C stations in Cell Two & 1 & 1 & 1 & 1 & 1 \\
\hline No of Inserter B stations in Cell Two & 2 & 2 & 2 & 2 & 2 \\
\hline Optimal Total Station Cost & 15537634 & 15961000 & 15537634 & 15537634 & $\begin{array}{c}1596100 \\
0\end{array}$ \\
\hline Number of Simulations & \multicolumn{2}{|c|}{21870} & 1120 & 1115 & 1115 \\
\hline Time in Hours & \multicolumn{2}{|c|}{29.94} & 1.44 & 1.66 & 1.47 \\
\hline
\end{tabular}

\subsection{Test Case 2}

In this problem, we have considered the print service center performance measure $\left(f_{1}\left(X_{k}\right)\right)$ as number of late jobs less than or equal to 0 . A print job is late if the completion time is more than its due. Table 4 illustrates the optimal and/or near optimal equipment configuration using existing approach with $\mathrm{N}$ equal to 30 ( $\mathrm{N}$ is the number of simulations replications for each design configuration) and simulation optimization approach with the parameters $\mathrm{n}=5, \mathrm{~L}=5, T_{\text {depth }}=100, \mathrm{r}=0.9$ and $\alpha=0.01$ for three different simulated annealing runs.

Table 4: Test case 2 results summary.

\begin{tabular}{|l|c|c|l|l|l|l|}
\hline & \multicolumn{2}{|l|}{$\begin{array}{l}\text { Exhaustive Search (Existing Ap- } \\
\text { proach ) }\end{array}$} & \multicolumn{2}{l|}{ Simulation Optimization Approach } \\
\hline $\begin{array}{l}\text { No of Pest } \\
\text { tions in Cell One }\end{array}$ & 1 & 1 & 1 & 1 & 1 & 1 \\
\hline $\begin{array}{l}\text { No of Inserter A } \\
\text { stations in Cell One }\end{array}$ & 2 & 3 & 1 & 1 & 1 & 3 \\
\hline $\begin{array}{l}\text { No of Inserter B } \\
\text { stations in Cell One }\end{array}$ & 2 & 2 & 2 & 2 & 3 & 2 \\
\hline $\begin{array}{l}\text { No of Printer B sta- } \\
\text { tions in Cell One }\end{array}$ & 1 & 1 & 1 & 1 & 1 & 1 \\
\hline $\begin{array}{l}\text { No of Printer C sta- } \\
\text { tions in Cell Two }\end{array}$ & 2 & 2 & 2 & 2 & 2 & 2 \\
\hline $\begin{array}{l}\text { No of Inserter B } \\
\text { stations in Cell Two }\end{array}$ & 2 & 2 & 3 & 3 & 2 & 2 \\
\hline $\begin{array}{l}\text { Optimal Total Sta- } \\
\text { tion Cost }\end{array}$ & 17517696 & 17941062 & 18537634 & 18537634 & 18537634 & 17941062 \\
\hline $\begin{array}{l}\text { Number of Simula- } \\
\text { tions }\end{array}$ & 21870 & & 1105 & 1115 & 1120 \\
\hline Time in Hours & & 29.94 & 1.77 & 1.56 & 1.50 \\
\hline
\end{tabular}




\section{Rai and Ettam}

\section{FUTURE WORK}

This paper presents a simulated annealing based simulation-optimization solution for optimally selecting equipment to design print shops. It describes how suitable abstractions and automation of the simulation tool can enable deployment of the Lean Document Production solution for cost-optimal equipment selection within a highly fragmented printing industry while optimizing key performance objectives such as maximum turnaround time, average turnaround time and number of late jobs. Future work includes evaluation of other optimization approaches, expansion of optimization criteria, speeding up of the optimization time via problem-dependent heuristics and parallelization and enabling the deployment of the solution via web-based tools.

\section{REFERENCES}

Ahmed, M. A., T. M. Alkhamis, and M. Hasan. 1997. "Optimizing Discrete Stochastic Systems using Simulated Annealing and Simulation." Computers \& Industrial Engineering, 32:823-836.

Alkhamis, T. M., and M. A. Ahmed. 2004. "Simulation Based Optimization using Simulated Annealing with Confidence Interval." In Proceedings of the 2004 Winter Simulation Conference, Edited by R. G. Ingalls, M. D. Rossetti, J. S. Smith, and B. A. Peters, 515-519. Piscataway, New Jersey: Institute of Electrical and Electronics Engineers, Inc.

Andradóttir, S., D. Goldsman, and S. H. Kim. 2005. "Finding the Best in the Presence of a Stochastic Constraint." In Proceedings of the 2005 Winter Simulation Conference, Edited by M. E. Kuhl, N. M. Steiger, F. B. Armstrong, and J. A. Joines, 732-738. Piscataway, New Jersey: Institute of Electrical and Electronics Engineers, Inc.

Batur, D., and S.-H. Kim. 2005. "Procedures for Feasibility Detection in the Presence of Multiple Constraints." In Proceedings of the 2005 Winter Simulation Conference, Edited by M. E. Kuhl, N. M. Steiger, F. B. Armstrong, and J. A. Joines, 692-698. Piscataway, New Jersey: Institute of Electrical and Electronics Engineers, Inc.

Fu, M. C., S. Andradóttir, J. S. Carson, F. Glover, C. R. Harrell, Y. C. Ho, J. P. Kelly, and S. M. Robinson. 2000. "Integrating Optimization and Simulation: Research and Practice." In Proceedings of the 2000 Winter Simulation Conference, Edited by J. A. Joines, R. R. Barton, K. Kang, and P. A. Fishwick, 610-616. Piscataway, New Jersey: Institute of Electrical and Electronics Engineers, Inc.

Haddock, J., and J. Mittenthal. 1992. "Simulation Optimization using Simulated Annealing." Computers \& Industrial Engineering, 22:387-395.

Harkan, I. A., and M. Hariga. 2007. "A Simulation Optimization Solution to the Inventory Continuous Review Problem with Lot Size Dependent Lead Time.” The Arabian Journal for Science and Engineering, 2:327-338.

Kabirian, A., and S. Olafsson. 2009. "Selection of the Best with Stochastic Constraints." In Proceedings of the 2009 Winter Simulation Conference, Edited by M. D. Rossetti, R. R Hill, B. Hohansson, A. Dunkin and R. G. Ingalls, 574-583. Piscataway, New Jersey: Institute of Electrical and Electronics Engineers, Inc.

Kirkpatrick, S., C. D. Gelatt, and M. P. Vecchi. 1983. "Optimization by Simulated Annealing.” Science, 220: 671- 680.

Luo, Y., and E. Lim. 2011. "Simulation Based Optimization Over Discrete Sets with Noisy Constraints." In Proceedings of the 2011 Winter Simulation Conference, Edited by S. Jain, R. R. Creasey, J. Himmerspach, K. P. White, and M. Fu, 4012-4025. Piscataway, New Jersey: Institute of Electrical and Electronics Engineers, Inc.

Prudius, A. A., and S. Andradóttir. 2005. "Two Simulated Annealing Algorithms for Noisy Objective Functions." In Proceedings of the 2005 Winter Simulation Conference, Edited by M. E. Kuhl, N. M. Steiger, F. B. Armstrong, and J. A. Joines, 798-802. Piscataway, New Jersey: Institute of Electrical and Electronics Engineers, Inc. 


\section{Rai and Ettam}

Pujowidianto, N. A., L. H. Lee, C. H. Chen, and C. M. Yap. 2009. "Optimal Computing Budget Allocation for Constraint Optimization." In Proceedings of the 2009 Winter Simulation Conference, Edited by M. D. Rossetti, R. R Hill, B. Hohansson, A. Dunkin and R. G. Ingalls, 584-586. Piscataway, New Jersey: Institute of Electrical and Electronics Engineers, Inc.

Rai, S. 2008. "Fat Tail Inputs in Manufacturing Systems." In Proceedings 2008 Industrial Engineering Research Conference, Edited by J. Flower and S. Mason, Vancouver, Institute of Industrial Engineers, Norcross, GA.

Rai, S., C. B. Duke, V. Lowe, C. Q. Trotter, and T. Scheermesser. 2009. "LDP Lean Document Production - O. R. - Enhanced Productivity Improvements for the Printing Industry." Interfaces, 39: 69-90.

Sandeman T., C. Stanford, C. Fricke, and P. Bodon. 2010. "Integrating Optimization and Simulation- a Comparison of Two Case Studies in Mine Planning." In Proceedings of the 2010 Winter Simulation Conference, Edited by B. Johansson, S. Jain, J. Montoya - Torres, J. Hugan, and E. Yücesan, 18981910. Piscataway, New Jersey: Institute of Electrical and Electronics Engineers, Inc.

Szechtman, R., and E. Yücesan. 2008. "A New Perspective on Feasibility Determination.” In Proceedings of the 2008 Winter Simulation Conference, Edited by S. J. Mason, R. R. Hill, L. Moench, O. Rose. Piscataway, New Jersey: Institute of Electrical and Electronics Engineers, Inc.

Zeng, Q., and Z. Yang. 2009. "Integrating Simulation and Optimization to Schedule Loading Operations in Container Terminals." Computers and Operations Research, 36: 1935-1944.

\section{AUTHOR BIOGRAPHIES}

SUDHENDU RAI is a Fellow at the Xerox Research Center in Webster, N.Y. He received his PhD. from MIT (1993), MS from Caltech (1989), and BTech from IIT, Kanpur (India) in 1988 - all in Mechanical Engineering. He is the lead inventor of the LDP Lean Document Production ${ }^{\circledR}$ solution that was a finalist at the 2008 Franz Edelman competition and got first place at IIE Lean Best Practice Award (2011). He holds 48 patents with 35 additional pending. He is a member of ASME, INFORMS, IIE and a senior member of IEEE. He was a finalist for the Rochester Engineer of the Year award in 2007.His e-mail address is Sudhendu.Rai@xerox.com.

RANJIT KUMAR ETTAM is a lead engineer at the Xerox Corporation in Bangalore, India. He received his MTech from IIT Kharagpur (2007) in Industrial Engineering and Management, and BTech (2005) from Jawaharlal Nehru Technological University (JNTU), Anantapur, India in Chemical Engineering. His research interests include Simulation Optimization, Multi Objective Optimization, and Meta-Heuristics. His e-mail address is Ranjit.Kumar2@xerox.com. 